\title{
Eotaxin Expression by Epithelial Cells and Plasma Cells in Chronic Asthma
}

\author{
Rakesh K. Kumar, Paul S. Thomas, Da-Qiang Seetoo, Cristan Herbert, \\ Andrew N. J. McKenzie, Paul S. Foster, and Andrew R. Lloyd \\ Inflammation Research Unit (RKK, PST, D-QS, CH, ARL), Department of Pathology, University of New South Wales, \\ Sydney; Prince of Wales Hospital Clinical School (PST), University of New South Wales, Sydney, Australia; Medical \\ Research Council Laboratory of Molecular Biology (ANJM), Cambridge, United Kingdom; and Department of \\ Biochemistry and Molecular Biology (PSF), John Curtin School of Medical Research, Australian National University, \\ Canberra, Australia
}

SUMMARY: Chemoattractants such as eotaxin are believed to play an important role in the recruitment of eosinophils into the airways in asthma. We investigated expression of eotaxin in the airway wall in a model of chronic human asthma, in which systemically sensitized mice were exposed to low mass concentrations of aerosolized antigen for 6 weeks. In these animals, the number of intraepithelial eosinophils in the airways was significantly increased 3 hours after exposure and declined by 24 hours. In parallel, immunoreactivity for eotaxin was strikingly up-regulated in airway epithelial cells and in inflammatory cells in the lamina propria. The latter were identified as plasma cells by double immunofluorescent labeling. Increased expression of eotaxin by epithelial cells and plasma cells was also demonstrated in a case of fatal human asthma. In contrast, sensitized mice that received a single exposure to a high mass concentration of aerosolized antigen exhibited delayed eosinophil recruitment, which did not correlate with eotaxin expression. Furthermore, in sensitized chronically exposed interleukin-13-deficient mice there was virtually no recruitment of eosinophils into the airways, although eotaxin expression was greater than or equal to that in wild-type mice. These results indicate that there are striking differences between acute and chronic exposure models in the time course of eotaxin expression and eosinophil recruitment. Although high eotaxin levels alone are not sufficient to cause recruitment of eosinophils into the airways, recurrent exposure may generate or up-regulate additional signals required for eosinophil chemotaxis. (Lab Invest 2002, 82:495-504).

$A$ sthma is an inflammatory disease of the airways, characterized by acute exacerbations superimposed upon a background of chronic inflammation and airway wall remodeling (Bousquet et al, 2000). In acute asthma, numerous eosinophils are recruited into the lamina propria and epithelium of the airways (Montefort et al, 1994; Shaver et al, 1997). The presence of intraepithelial eosinophils is regarded as a distinctive histopathological feature of the disease (Bousquet et al, 1990), although the specific role of these inflammatory cells in the pathogenesis of the functional abnormalities associated with an acute attack remains poorly understood. Eosinophils release a variety of potentially toxic granule products (Kroegel et al, 1994; Weller, 1991), which have long been regarded as important in causing epithelial injury leading to airway hyperreactivity (AHR) (Coyle et al, 1994; Frigas et al, 1981). However, recent studies using a humanized antibody to interleukin-5 (IL-5), which inhibits accumulation of eosinophils, have provided persuasive evidence that AHR can develop in the ab-

Received December 12, 2001.

This work was supported by a grant from Asthma New South Wales. Address reprint requests to: $R$. K. Kumar, Department of Pathology, University of New South Wales, Sydney, Australia 2052. E-mail: R.Kumar@unsw.edu.au sence of eosinophil recruitment (Leckie et al, 2000). Nevertheless, eosinophils clearly do play a major role in acute asthma, and an increased number of eosinophils in sputum is predictive of an exacerbation of the illness (Jatakanon et al, 2000). Inhibition of recruitment of eosinophils is therefore attractive as a potential therapeutic strategy.

Leukocyte recruitment to the site of inflammation typically involves both the increased local generation of chemoattractant mediators as well as enhanced expression or increased affinity of adhesion ligands and their counter-receptors on leukocytes and endothelial cells (Bochner, 2000). In the case of eosinophils, a range of relatively selective chemoattractants for these cells has been identified, including eicosatetraenoic acid derivatives (Guilbert et al, 1999) and members of the CC chemokine family, notably eotaxin, RANTES, and various molecules of the monocyte chemoattractant protein (MCP) group (Kita and Gleich, 1996; Rothenberg et al, 1999; Teran, 2000). Potentially selective adhesion molecules that may play a critical role in eosinophil accumulation have also been described, in particular very late antigen 4 (VLA-4) and vascular cell adhesion molecule-1 (VCAM-1) (Bochner, 2000; Henricks et al, 1997).

In human asthma, increased expression of various eosinophil-selective chemoattractants has been re- 
ported (Alam et al, 1996; Lamkhioued et al, 1997; Tillie-Leblond et al, 2000; Ying et al, 1999) and increased expression of VCAM-1 (Fukuda et al, 1996) has been demonstrated. However, the inherent difficulty of human studies has made it difficult to assess the relative importance of different mediators and mechanisms during the evolution of an allergic inflammatory response. Despite this, the specificity of eotaxin as a chemoattractant for eosinophils has led to widespread acceptance of the notion that this chemokine is likely to play an important role in the accumulation of eosinophils in tissues (Garcia-Zepeda et al, 1996; Ying et al, 1997).

Animal experimental studies lend considerable credence to the notion that eotaxin plays a pivotal role in eosinophil recruitment in allergic inflammation (Gonzalo et al, 1996, 1998; Mould et al, 1997). These studies also provide support for the regulation of eotaxin expression by so-called Th2 cytokines, notably interleukin-13 (IL-13) (Li et al, 1999; Teran et al, 1999; Zhu et al, 1999). However, it may be inappropriate to extrapolate to human asthma from studies using these experimental models, because the chronic inflammation and airway wall remodeling that characterize human asthma are poorly replicated by most rodent models of allergic bronchopulmonary inflammation (Griffiths-Johnson et al, 1997; Nakamura et al, 1999). Moreover, in most models, the inflammatory response is characterized by a high density of lymphocytes and eosinophils surrounding the airways and extending to the blood vessels, which is unlike chronic asthma (Cohn, 2001).

We have described an improved model of chronic asthmatic inflammation of the airways in mice (Temelkovski et al, 1998). This involves systemic sensitization of high immunoglobulin $\mathrm{E}$ (IgE)-responder BALB/c mice to ovalbumin and inhalational challenge with low mass concentrations of aerosolized antigen for 30 minutes/day, 3 days/week for 6 weeks. This approach consistently elicits lesions typical of chronic human asthma, including chronic inflammation in the lamina propria with accumulation of Jymphocytes, plasma cells, and macrophages, as well as epithelial hypertrophy, mucous cell hyperplasia/metaplasia, and subepithelial fibrosis. In contrast to previously reported mouse models of asthma, there are fewer total inflammatory cells and no evidence of pulmonary parenchymal inflammation, but numerous intraepithelial eosinophils are seen in the upper airways. In addition, the mice exhibit marked AHR to an inhaled cholinergic agonist. Thus, this model replicates most of the features that are typical of the chronic human disease.

In this study, we examined the relationship between eosinophil recruitment and expression of eotaxin in this long-term, low-exposure model of chronic experimental asthma and compared the findings with those obtained in a short-term, high-exposure model of allergic bronchopulmonary inflammation. We also investigated eotaxin expression in fatal human asthma. In addition, we examined the regulation of eotaxin expression by IL-13 in gene-targeted mice deficient in their ability to produce this cytokine. Our results suggest that there are striking differences between acute and chronic exposure models in the time course of eotaxin expression and eosinophil recruitment, that plasma cells express high levels of eotaxin in both the chronic murine model and in fatal human asthma, and that eotaxin expression is not by itself sufficient to cause recruitment of eosinophils.

\section{Results}

\section{Recruitment of Eosinophils in Chronic and Acute Exposure Models}

Sensitized BALB/c mice that had been repeatedly exposed to low levels of aerosolized antigen for 6 weeks exhibited recruitment of numerous eosinophils into the tracheal epithelium at 3 hours following the final exposure (Fig. 1A). Numbers of intraepithelial eosinophils remained high at 6 hours post-exposure but declined considerably by 24 hours, although remaining significantly elevated compared to nonimmunized nonexposed animals $(p<0.001$ for all three time points, Fig. 2). There was no evidence of any inflammatory response in the lungs of these mice.

In contrast, sensitized animals that received a single uncontrolled exposure to aerosolized ovalbumin had few eosinophils in the tracheal epithelium at 3 hours. The numbers of these cells then increased rapidly, reaching levels similar to those in chronically exposed animals at 6 hours post-exposure, but subsequently declined (Fig. 2). At 24 hours post-exposure, the lungs of these mice exhibited a florid perivascular and peribronchiolar inflammatory response, with accumulation of numerous eosinophils (not shown), although intraepithelial eosinophils were conspicuously absent. In nonsensitized mice, virtually no recruitment of eosinophils was observed following a single high exposure to aerosolized antigen (Fig. 2).

\section{Expression of Eotaxin in Chronic and Acute Exposure Models}

In the chronic exposure model, immunohistochemical staining for eotaxin revealed not only moderate-tostrong expression in the airway epithelium but also intense immunoreactivity in the cytoplasm of inflammatory cells in the lamina propria (Fig. 1B). These latter cells had the morphological appearance of plasma cells or plasmacytoid lymphocytes. No staining was observed when the primary antibody was omitted. Furthermore, both the epithelial and the inflammatory cell reactivity could be completely inhibited by preincubation of the antibody with the corresponding blocking peptide (Fig. 1C). In the acute exposure model, immunoreactivity was only observed in the epithelium.

Semiquantitative grading of immunoreactivity in the tracheal epithelium of chronically exposed, sensitized acutely exposed, and nonsensitized acutely exposed mice revealed striking differences in the intensity and time course of expression. In chronically exposed mice, high levels of expression were obvious at 3 

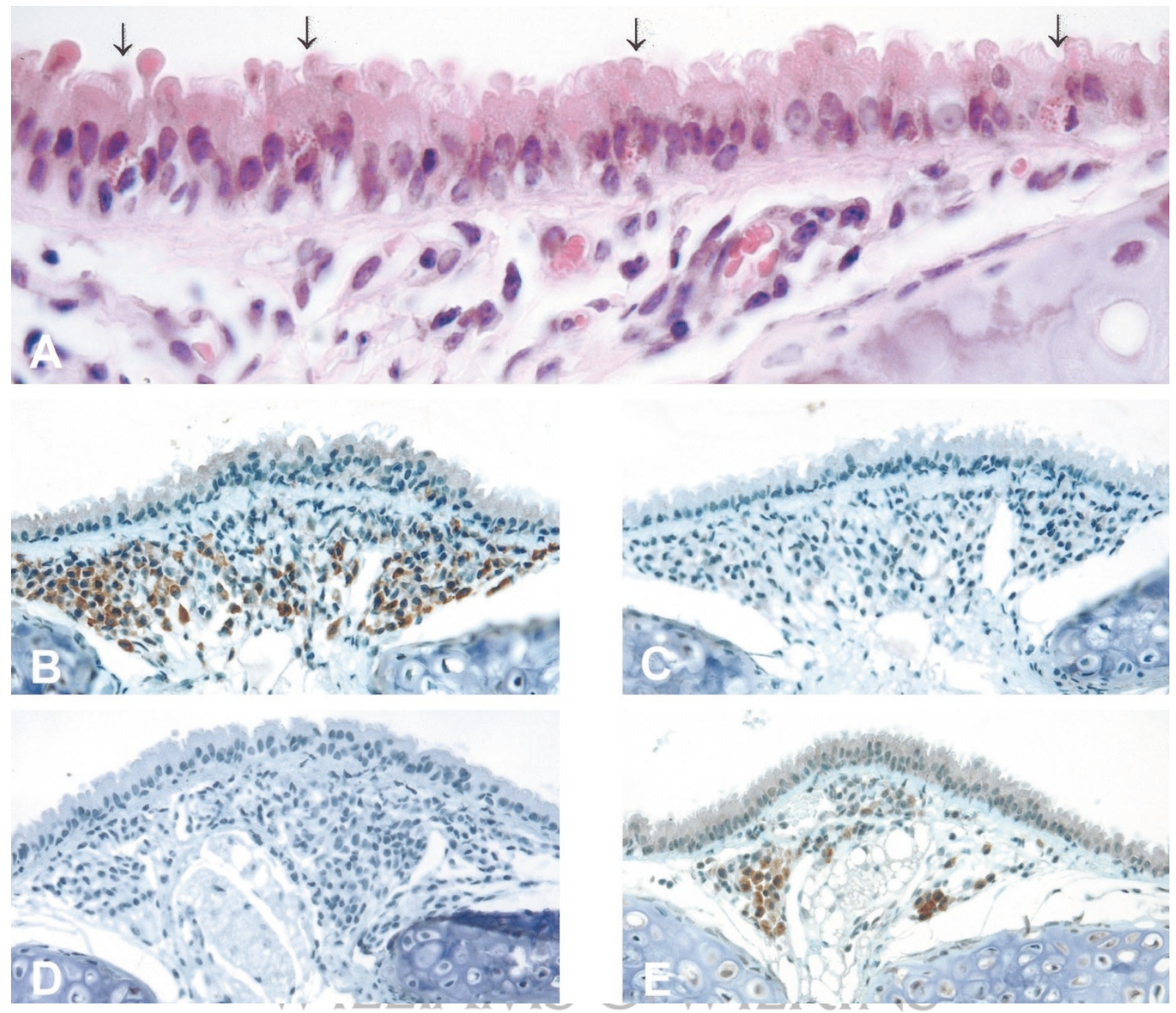

\section{Figure 1.}

A, Eosinophils within the tracheal epithelium of a sensitized chronically exposed BALB/C mouse at 3 hours following exposure to ovalbumin. B, Immunoperoxidase staining for eotaxin in the airway wall of a sensitized chronically exposed BALB/c mouse at 3 hours following exposure to ovalbumin. Using a concentration of antieotaxin four-fold lower than that required for optimal staining, there is still moderate immunoreactivity of airway epithelial cells and strong staining of the cytoplasm of plasmacytoid inflammatory cells in the lamina propria. C, Same region from a consecutive section, demonstrating virtually complete inhibition of staining by preincubation of the antibody with the corresponding blocking peptide. D, Absence of immunoreactivity for eotaxin in the airway wall of a sensitized chronically exposed BALB/c mouse at 24 hours following exposure to ovalbumin. E, Immunoperoxidase staining for eotaxin in the trachea of a sensitized chronically exposed IL-13 -/- mouse at 3 hours following exposure to ovalbumin, demonstrating strong immunoreactivity of both airway epithelial cells and plasma cells in the lamina propria.

hours post-exposure $(p<0.05$ compared with normal animals), but these declined sharply at 6 hours, and virtually no staining was detectable after 24 hours (Fig. 1D). In contrast, the levels of expression in the epithelium of sensitized, acutely exposed mice were comparably high at 3 hours, but hardly declined thereafter. Unexpectedly, we found that eotaxin expression progressively increased in the epithelium of nonsensitized acutely exposed mice, so that at 24 hours postexposure it was similar to that observed in sensitized mice at 3 hours $(p<0.05$ compared with normal animals) (Table 1).

To confirm the identity of the eotaxin-expressing cells in the lamina propria of the airways in chronically exposed mice at 3 hours post-exposure, we performed double immunofluorescence staining for

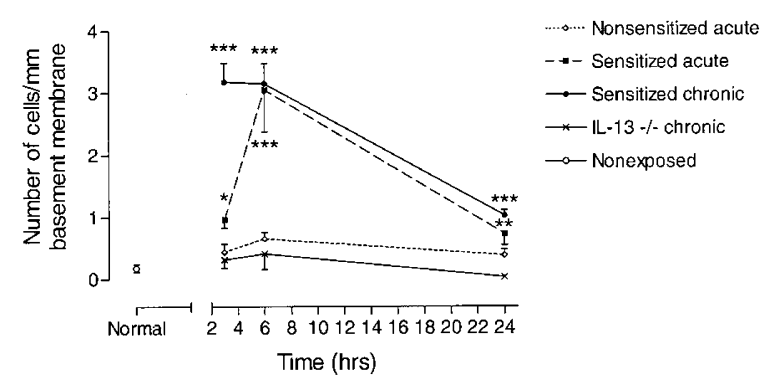

Figure 2.

Numerical density of intraepithelial eosinophils (mean \pm SEM) in the tracheas of nonsensitized acutely exposed, sensitized acutely exposed, and sensitized chronically exposed mice. Significant differences compared to normal nonexposed control animals are shown as ${ }^{*}=P<0.05,{ }^{* *}=P<0.01,{ }^{* *}=$ $P<0.001$. 
Table 1. Eotaxin Expression in the Airway Epithelium

\begin{tabular}{ccccc}
\hline Time $(\mathrm{h})$ & Nonsensitized Acute & Sensitized Acute & Sensitized Chronic & IL-13 -/- Chronic \\
\hline 3 & $1.17 \pm 0.17$ & $2.00 \pm 0.52^{*}$ & $2.17 \pm 0.31^{*}$ & $2.17 \pm 0.17^{\star *}$ \\
6 & $1.50 \pm 0.42$ & $2.00 \pm 0.45^{*}$ & $0.83 \pm 0.31$ & $2.50 \pm 0.34^{* *}$ \\
24 & $2.17 \pm 0.48^{*}$ & $1.67 \pm 0.42$ & $0.33 \pm 0.21$ & $1.50 \pm 0.22$ \\
\hline
\end{tabular}

Data are grades of immunoreactivity for eotaxin, expressed as mean \pm SEM. The mean grade in normal nonexposed control animals was $0.33 \pm 0.21$. Significant differences compared to these control animals are shown as ${ }^{*}=p<0.05,{ }^{*}=p<0.01$.

eotaxin and mouse immunoglobulins. As shown in Figure 3, A to C, there was intense expression of eotaxin by inflammatory cells in the lamina propria, which colocalized with expression of cytoplasmic immunoglobulins, indicating that these were immunoglobulin-producing, B-lymphocyte-derived plasma cells. In addition, staining for eotaxin was also observed in the tracheal epithelium, whereas staining for immunoglobulins was also observed in blood vessels.

The intensity of immunoreactivity of plasma cells for eotaxin was semiquantitatively assessed using a similar approach to that employed for the epithelium. The intense staining observed at 3 hours post-exposure declined with time, but the decline was less marked than that observed for the epithelium (Table 2), although some animals exhibited no staining at 24 hours (Fig. 1D).

\section{Eosinophil Recruitment and Eotaxin Expression in IL-13 -/- Mice}

In IL-13 - /- mice that had been sensitized and chronically exposed to low levels of aerosolized antigen for 6 weeks, there was little evidence of recruitment of eosinophils into the tracheal epithelium at any of the time points studied (Fig. 2), which was consistent with our previous observations in these mice at 18 hours post-exposure (Kumar et al, 2002). Surprisingly, however, there was strong expression of eotaxin both by tracheal epithelial cells and by plasma cells in the lamina propria in these animals (Fig. 1E). Quantification revealed significantly greater expression of eotaxin in tracheal epithelium by $\mathrm{IL}-13-/-$ mice compared with wild-type mice at 6 hours postexposure, with persisting elevated expression at 24 hours (Table 1). Expression of eotaxin by plasma cells in the airway wall of IL-13 -/ mice was at least comparable to that in wild-type mice (Table 2), with a tendency for increased expression at 6 hours, although the observed difference was not statistically significant.

\section{Eotaxin Expression in Fatal Human Asthma}

Because the antibody to mouse eotaxin that we employed in these studies cross-reacts with human eotaxin, we were also able to examine expression of eotaxin in human asthmatic airways. As a pilot investigation, we immunostained sections from a single patient with fatal asthma, to assess whether the pattern of eotaxin expression was similar to that observed in the murine chronic exposure model and, in partic- ular, whether plasma cells in the airway wall exhibited immunoreactivity for eotaxin. We found that immunostaining of the epithelium was prominent, together with staining of a variety of inflammatory cells in the lamina propria (Fig. 4A). There was minimal nonspecific staining when the primary antibody was omitted (Fig. 4B). Notable among the immunoreactive cells in the airway wall were cells with abundant cytoplasm and eccentric nuclei, which had the characteristic "clock-face" appearance of plasma cells (Fig. 4C).

\section{Discussion}

In this study, we investigated eosinophil recruitment and the potential role of eotaxin, using a long-term inhalational exposure model of asthma in mice, which replicates the chronic inflammation and airway wall remodeling that characterize the human disease. We wish to emphasize that, because these animals do not develop a significant alveolitis, relatively few inflammatory cells are present in bronchoalveolar lavage fluid and lavage is thus an inappropriate method of quantifying inflammation in this model. We therefore employed morphometric quantification of eosinophils within the airway epithelium and of chronic inflammatory cells within the lamina propria. Although the absolute numbers of eosinophils recruited into the airways are smaller than in short-term, high-level exposure models, the increase is significant at $p<0.001$ compared with controls. Our results demonstrate that there are significant differences in the pattern of recruitment of eosinophils between this model and the short-term, high-level exposure models of allergic bronchopulmonary inflammation that have been extensively used to examine pathogenetic mechanisms of asthma. Furthermore, our data raise important questions about the biology of eosinophil recruitment and the role of eotaxin as a chemoattractant for these cells.

With respect to tissue accumulation of eosinophils, in the chronic exposure model the number of intraepithelial eosinophils in the airways was strikingly increased at 3 hours post-exposure. Eosinophil numbers remained high at 6 hours but declined to lower levels by 24 hours. These observations were in contrast to our findings in an acute exposure model, in which intraepithelial eosinophils are usually said to be absent (Korsgren et al, 1997). We found that, although there was no accumulation of eosinophils in the epithelium of the intrapulmonary bronchioles, large numbers of eosinophils were identified in the tracheal epithelium of these animals. However, the timing of 
accumulation of these cells was quite different from that observed in the chronic exposure model, in that there was little evidence of eosinophil recruitment at 3 hours, although this reached comparable levels by 6 hours post-exposure. Recruitment of eosinophils was clearly dependent upon prior sensitization, because no cellular accumulation was observed in nonsensitized control animals. Our findings suggest that different mechanisms for eosinophil recruitment are operating in the chronic, as opposed to the acute, exposure models, possibly related to the much higher dose of antigen deposited in the airways of the latter. The data also imply that chronic exposure to allergen somehow primes the airways for much more rapid recruitment of eosinophils following challenge.

A possible mechanism for the rapid recruitment of eosinophils in the chronic, compared with the acute,
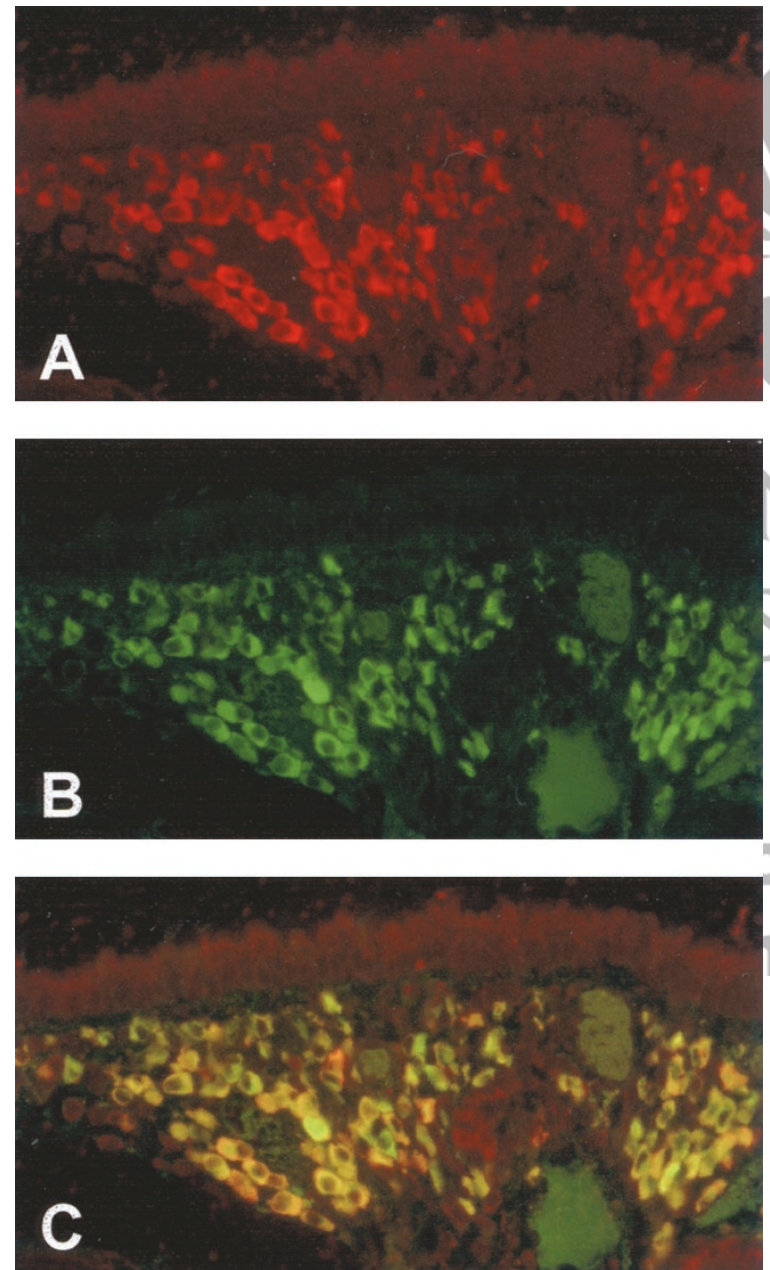

Figure 3.

A, Double label immunofluorescence staining demonstrating eotaxinimmunoreactive epithelium and inflammatory cells in the lamina propria of the trachea at 3 hours following exposure to ovalbumin, using an Alexa 568labeled reporter antibody which fluoresces red. B, Same field demonstrating immunoglobulin-containing plasma cells, using an fluorescein isothiocyanate (FITC)-labeled antibody which fluoresces green. C, Digitally merged image of fields in $A$ and $B$, demonstrating colocalization of eotaxin in inflammatory cells in the lamina propria with cytoplasmic immunoglobulins, seen as yellow. Note non-colocalizing staining for eotaxin in the tracheal epithelium and for immunoglobulins in blood vessels.
Table 2. Eotaxin Expression by Plasma Cells

\begin{tabular}{ccc}
\hline Time $(\mathrm{h})$ & Sensitized Chronic & IL-13 $-/-$ Chronic \\
\hline 3 & $2.83 \pm 0.17$ & $3.00 \pm 0.0$ \\
6 & $1.83 \pm 0.48$ & $2.83 \pm 0.17$ \\
24 & $1.83 \pm 0.60$ & $1.67 \pm 0.21$ \\
\hline
\end{tabular}

Data are grades of immunoreactivity for eotaxin, expressed as mean \pm SEM.

exposure model might be that there is up-regulation of pathways for the generation of chemoattractants. A likely candidate in this regard is eotaxin, which is a relatively specific chemoattractant for eosinophils. We therefore examined expression of eotaxin in the airway epithelium in these two models by immunohistochemical staining with a polyclonal goat primary antibody to eotaxin, which was generated by immunization with a 19-amino acid peptide from mouse eotaxin that ex-

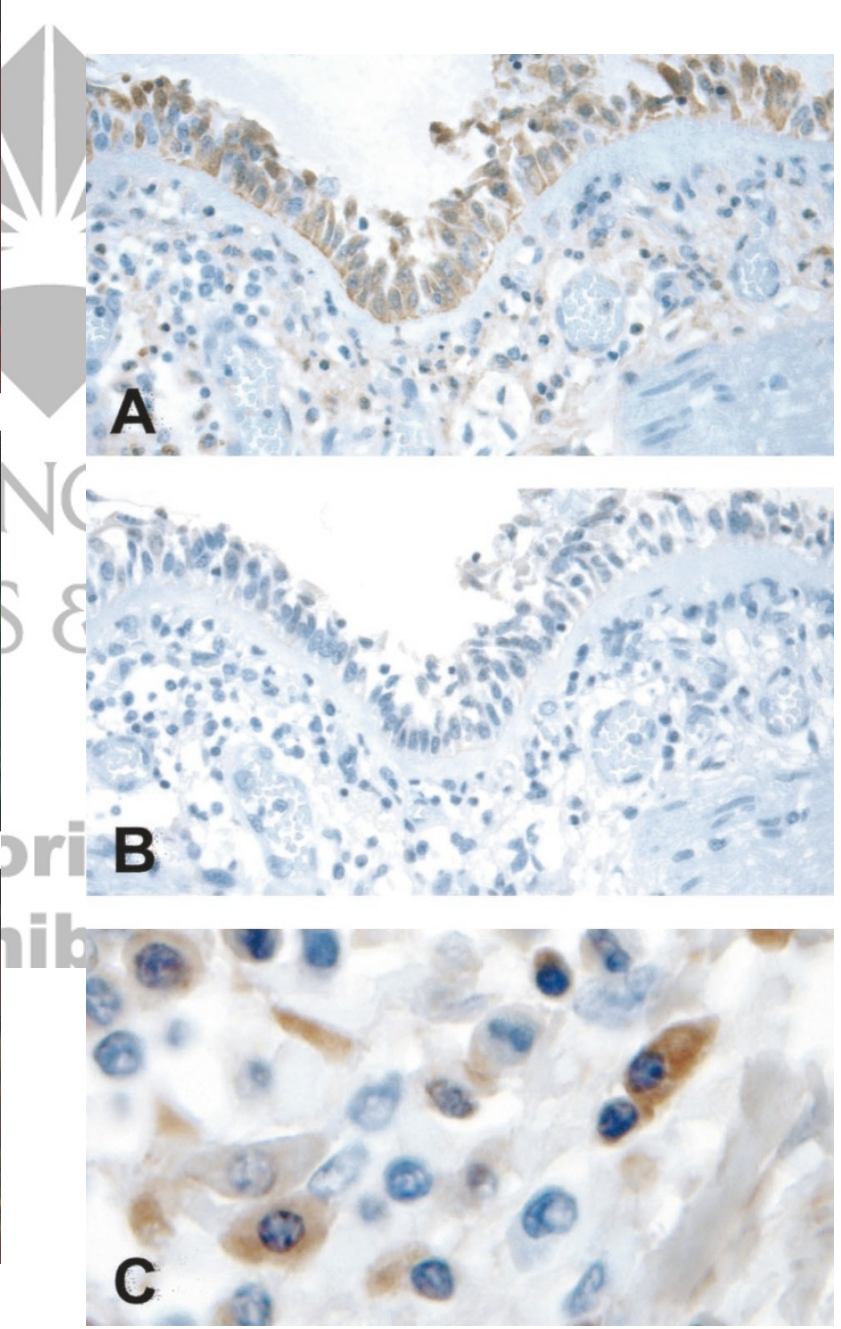

Figure 4.

A, Immunoperoxidase staining for eotaxin in a patient who died of acute severe asthma. In this peripheral airway, epithelial cells are strongly immunoreactive, as are numerous inflammatory cells in the lamina propria. B, Same region from a consecutive section, demonstrating virtually complete absence of staining when the primary antibody was omitted. C, High magnification of a region of the lamina propria from the section shown in $\mathrm{A}$, demonstrating cells with the characteristic "clock-face" nuclear morphology of plasma cells that were strongly immunoreactive for eotaxin. 
hibits no significant homology to other members of the eotaxin family or to other chemokines. At 3 hours following antigen challenge, expression of eotaxin was strikingly up-regulated in airway epithelial cells and plasmacytoid B-lymphocytes in the lamina propria in sensitized, chronically exposed mice. The identity of the latter cells was established by double immunofluorescent labeling. Semiquantitative assessment of immunoreactivity for eotaxin revealed that expression of the protein declined rapidly in the tracheal epithelium of chronically exposed mice. This finding was in contrast to observations in the acute exposure model of allergic bronchopulmonary inflammation, in which sensitized animals exhibited rapid induction of eotaxin expression in the epithelium, but a much slower decline. The duration of expression of eotaxin may be related to antigen dose, and the results suggest that different regulatory pathways for induction of eotaxin expression are operative in the low- and high-level exposure models. This possibility is supported by the unexpected finding that expression was induced at a lower level in nonsensitized acutely exposed mice and rose noticeably after 24 hours, despite the lack of eosinophil recruitment into the airway epithelium in these animals. Together, these data imply that expression of eotaxin may be a nonspecific response following high-level exposure, but that the time course of induction might be modified by sensitization.

In complete contrast to what might have been predicted on the basis of published reports ( $\mathrm{Li}$ et al, 1999; Matsukura et al, 2001; Zhu et al, 1999), we found that in sensitized chronically exposed IL-13 $-/-$ mice, eotaxin expression was undiminished, both in epithelial cells and plasmacytoid cells. Indeed the intensity of expression in the epithelium at both 6 and 24 hours was higher than in wild-type mice, despite the virtual absence of intraepithelial eosinophils in the knockout mice.

In the chronic exposure model of asthma, a substantial proportion of inflammatory cells in the lamina propria is comprised of antigen-specific immunoglobulin G-producing B-lymphocytes with the morphology of plasma cells (Kumar et al, 2000a). In sensitized chronically exposed wild-type mice, expression of eotaxin by plasmacytoid cells in the lamina propria of the trachea declined more slowly than in the epithelium, but the induction of immunoreactivity following antigen challenge and the decline at 24 hours postexposure both indicate that this response was related to inhalational exposure to ovalbumin. Although there was no statistically significant difference compared to wild-type mice, the intensity of expression of eotaxin in plasma cells was again higher at 6 hours postexposure in the IL-13 -/- mice. These observations could imply that in the IL-13-/- animals, a negative feedback mechanism operative in wild-type mice is no longer functional.

The different time course of eosinophil accumulation in the chronic, compared with the acute, exposure models, together with the data on eotaxin expression in the airway epithelium in the two models and in IL-13 $-/-$ mice, strongly suggest that more than one signal is required for recruitment of eosinophils into the airways. Furthermore, recurrent exposure appears to generate or up-regulate the additional signal or signals. Although the findings do not exclude an important role for eotaxin, high eotaxin levels alone are clearly not sufficient to cause eosinophil chemotaxis. This inference is supported by the observation that there was virtually complete absence of eosinophil recruitment in the nonsensitized acutely exposed mice, even though these animals did exhibit modest expression of eotaxin. Even more persuasive is the finding that in the IL-13-/- mice, which also had almost no intraepithelial eosinophils, expression of eotaxin was comparable with wild-type mice and was sustained for a longer period. The additional signal or signals might include rapidly generated mediators, such as eosinophil-selective arachidonic acid metabolites (Guilbert et al, 1999), which may be particularly important in the early recruitment of eosinophils; a variety of other eosinophil chemoattractant cytokines, eg, macrophage inflammatory protein- $1 \alpha$ (Campbell et al, 1998; Gonzalo et al, 1998); as well as molecules involved in the adhesion of eosinophils to vascular endothelium (Burke-Gaffney and Hellewell, 1998; Nakajima et al, 1994). In this context, IL-13 is able to up-regulate the expression of eosinophil-selective adhesion molecules such as VCAM-1 and P-selectin on endothelial cells (Bochner et al, 1995; Woltmann et al, 2000), and it is possible that absence of such upregulation accounts for the lack of eosinophil recruitment in IL-13 -/- mice. It may also be noteworthy that proinflammatory cytokines such as tumor necrosis factor $-\alpha$ can contribute to the up-regulation of expression of both eosinophil-selective chemokines (Teran et al, 1999) and relevant adhesion molecules (Yamamoto et al, 1998)

As has long been recognized, plasma cells constitute a significant subpopulation in the airway wall in human asthmatics (Laitinen et al, 1993). Our novel demonstration of eotaxin expression by plasma cells in the chronic exposure model of asthma appears to be relevant to the human disease, because similar expression of eotaxin was observed in a case of fatal human asthma. However, because we do not have access to a bank of tissue from human asthmatics, our findings should be regarded as preliminary, and further investigation of this response would be appropriate. We also note that among the inflammatory cells in the airway wall are macrophages, lymphocytes, and eosinophils, all of which can produce eotaxin. A presently unresolved issue is the relative importance of expression of eotaxin by different populations of inflammatory cells and by airway epithelial cells in asthma. Another interesting question is whether eotaxin might be expressed by plasma cells at other sites, eg, the gut.

The results of this study highlight some important differences between the chronic and acute exposure models of asthmatic inflammation in mice. The time course of eosinophil recruitment, as well as both the time course and the intensity of expression of eotaxin in the epithelium, are notably divergent. Moreover, the 
demonstration that plasma cells express eotaxin following antigen challenge is not possible in acute exposure models because accumulation of plasma cells does not occur in such models. In the context of the potential importance of recruitment of eosinophils into the epithelium of the airways in asthma (Henricks et al, 1997), it is clearly desirable that appropriate experimental models are employed to achieve a better understanding of this process.

\section{Materials and Methods}

\section{Animals}

Specific pathogen-free female BALB/c mice were obtained from the Biological Resources Centre, University of New South Wales, Sydney, Australia. Mice on a BALB/c background, genetically deficient in their ability to produce IL-13 (IL-13 -/- mice) (McKenzie et al, 1998), were obtained from the Animal Services Division, Australian National University, Canberra, Australia. Animals were aged approximately 8 weeks at the commencement of experimental studies. They were maintained in a laminar flow holding unit (Gelman Sciences, Sydney, Australia) and housed in autoclaved cages on autoclaved bedding in an airconditioned room on a 12-hour light/dark cycle. Irradiated food and acidified water were provided ad libitum throughout. All experimental procedures complied with the requirements of the Animal Care and Ethics Committee of the University of New South Wales (ref. no. 98/29).

\section{Sensitization and Inhalational Exposure}

For the chronic exposure model, these were performed essentially as previously described (Temelkovski et al, 1998). In brief, mice were sensitized by an intraperitoneal injection of $50 \mu \mathrm{g}$ of alum-precipitated chicken egg ovalbumin (Grade V, $\geq 98 \%$ pure, Sigma, St. Louis, Missouri; unless otherwise specified, all chemicals were obtained from this source) 21 days and 7 days before inhalational exposure. Animals were exposed to aerosolized ovalbumin for 30 minutes/day on 3 days/week for 6 weeks in a whole-body inhalation exposure system (Unifab Corporation, Kalamazoo, Michigan). During the exposures, the animals were held in wire flow-through cage racks, and filtered air was drawn through the $0.5 \mathrm{~m}^{3}$ inhalation chamber at a flow rate of $250 \mathrm{l} /$ minutes. A solution of $2.5 \%$ ovalbumin in normal saline was aerosolized by delivery of compressed air to a sidestream jet nebulizer (Trimed, Sydney, Australia) and injected into the airstream entering the chamber. The concentration and size distribution of particles within the breathing zone of the mice were continuously and cumulatively monitored using a light scatter device (PCAM-TX; PPM, Knoxville, Tennessee). Particle concentration was maintained in the range 10 to $20 \mathrm{mg} / \mathrm{m}^{3}$ by controlling the airflow into the nebulizer. Experimental groups of 6 animals were killed 3, 6, and 24 hours after the last exposure.
For the acute exposure model, sensitization was performed as above. Both sensitized and nonsensitized animals received a single exposure to a high mass concentration of aerosolized ovalbumin for 30 minutes. No regulation of nebulizer airflow was employed for this exposure, and particle concentration was estimated to be $\geq 100 \mathrm{mg} / \mathrm{m}^{3}$ under these conditions. Groups of 6 animals were killed 3, 6, and 24 hours after exposure.

\section{Collection of Tissues}

Animals were killed by exsanguination following an overdose of pentobarbital, and the lungs were perfused with $0.9 \%$ saline under a pressure of $40 \mathrm{~cm} \mathrm{H}_{2} \mathrm{O}$ for 60 seconds to remove blood from the pulmonary capillary bed. The trachea was then cannulated with a blunted \#19 needle, and the lungs were inflated with $10 \%$ buffered formalin. After fixation overnight, the longitudinally oriented trachea and a horizontal slice from the mid-zone of the single-lobed left lung were embedded in paraffin. Sections were cut at $5 \mu \mathrm{m}$ and stained with hematoxylin and eosin for assessment of eosinophil recruitment, or immunostained for assessment of eotaxin expression. Sections of human airways from a patient who died as a result of acute severe asthma were obtained from archival paraffinembedded blocks.

\section{Immunohistochemistry}

Expression of eotaxin was demonstrated using a goat polyclonal antibody to a 19-amino acid peptide corresponding to an epitope at the carboxy terminus of mouse eotaxin (sc-6182; Santa Cruz Biotechnology, Santa Cruz, California). The amino acid sequence of this peptide exhibits no significant homology to other members of the eotaxin family or to other chemokines. The antibody recognizes mouse, rat, and human eotaxin, but does not cross-react with other chemokines. Immunostaining was performed on paraffin sections with antigen retrieval by boiling in $0.01 \mathrm{M}$ citrate buffer ( $\mathrm{pH}$ 6.0) for 10 minutes in a microwave. Nonspecific binding was blocked by incubation for 15 minutes with $50 \%$ normal rabbit serum diluted in phosphate-buffered saline (PBS). For routine immunostaining, this antibody was applied to sections at a concentration of $2.5 \mu \mathrm{g} / \mathrm{ml}$ in PBS containing $0.075 \%$ Brij-35 detergent for 60 minutes at room temperature. To demonstrate the specificity of labeling with antieotaxin, a four-fold lower concentration of antibody was used. This was preincubated for 10 minutes with either $175 \mu \mathrm{g} / \mathrm{ml}$ of the corresponding blocking peptide (sc-6182P, Santa Cruz) or with 1\% bovine serum albumin, and the preincubated samples were applied to consecutive sections. Slides were washed four times with PBS after this and each subsequent incubation.

For immunoperoxidase staining, bound antibody was detected by sequential 30 minutes incubations with a 1:200 dilution of rabbit anti-goat immunoglobulins (Dako, Sydney, Australia) in PBS-Brij containing 
$1 \%$ normal mouse serum, followed by a 1:100 dilution of goat peroxidase-antiperoxidase complex (Dako). Diaminobenzidine was used as the substrate, and sections were lightly counterstained with hematoxylin for 30 seconds.

For double-label immunofluorescence staining, paraffin sections were stained essentially as previously described (Kumar et al, 2000b). Slides were dewaxed, blocked, and incubated with goat anti-mouse eotaxin as above. Bound antibody was detected by incubating for 45 minutes with $10 \mu \mathrm{g} / \mathrm{ml}$ of rabbit anti-goat immunoglobulins conjugated to Alexa 568 (Molecular Probes, Eugene, Oregon), which has excitation/emission maxima of $573 / 596 \mathrm{~nm}$, similar to lissamine rhodamine. Slides were then incubated for 45 minutes with a 1:10 dilution of $F(a b)_{2}$ goat anti-mouse immunoglobulins conjugated to fluorescein isothiocyanate (FITC, Dako). After mounting in Vectashield (Vector Laboratories, Burlingame, California), slides were sealed with clear nail lacquer and examined with an Olympus BX60 microscope equipped with a $100 \mathrm{~W}$ mercury burner for epifluorescence illumination. For both fluorescence and brightfield microscopy, images were captured with a Spot Cooled Color Digital camera (Diagnostic Instruments, Sterling Heights, Michigan).

\section{Morphometry}

To quantify intraepithelial eosinophils in the trachea, brightfield images of hematoxylin and eosin-stained sections were captured with the Spot camera, which was calibrated with a reference measurement slide. The length of the epithelial basement membrane for the entire section was measured by tracing using the Spot software and a $\times 4$ objective. The full length of the epithelial surface was then examined using a $\times 100$ oil immersion objective to enumerate eosinophils, which were readily identified on the basis of their strongly staining cytoplasmic granules. The data were expressed as number of cells per millimeter of epithelial basement membrane for individual animals.

Intensity of immunoreactivity was semi-quantitatively scored as grade $0=$ no staining, grade $1=$ weak staining, grade $2=$ moderate staining, and grade $3=$ strong staining. All grading was performed by a single observer blinded to the identity of the samples and slides were presented in random order for examination.

\section{Statistical Analysis}

Results are presented as arithmetic mean \pm standard error for each experimental group. For numbers of intraepithelial eosinophils, an initial one-way analysis of variance followed by Newman-Keuls multiple comparison test was used to examine differences between groups. Comparison of the intensity of immunoreactivity was based upon grading and therefore employed a nonparametric Kruskal-Wallis test followed by Dunn's multiple-comparison procedure or a MannWhitney test, as appropriate. The software package GraphPad Prism (GraphPad Software, San Diego,
California) was used for all data analysis and preparation of graphs.

\section{Acknowledgement}

We thank Angelina Enno and Gavin McKenzie for invaluable assistance in the preparation and staining of tissue sections.

\section{References}

Alam R, York J, Boyars M, Stafford S, Grant JA, Lee J, Forsythe P, Sim T, and Ida N (1996). Increased MCP-1, RANTES, and MIP- $1 \alpha$ in bronchoalveolar lavage fluid of allergic asthmatic patients. Am J Respir Crit Care Med 153:1398-1404.

Bochner BS (2000). Road signs guiding leukocytes along the inflammation superhighway. J Allergy Clin Immunol 106:817828.

Bochner B, Klunk D, Sterbinsky S, Coffman R, and Schleimer $R$ (1995). IL-13 selectively induces vascular cell adhesion molecule-1 expression in human endothelial cells. J Immunol 154:799-803.

Bousquet J, Chanez P, Lacoste JY, Barneon G, Ghavanian N, Enander I, Venge P, Ahlstedt S, Simony-Lafontaine J, Godard $P$, and Michel FB (1990). Eosinophilic inflammation in asthma. N Engl J Med 323:1033-1039.

Bousquet J, Jeffery PK, Busse WW, Johnson M, and Vignola A (2000). Asthma: From bronchoconstriction to airways inflammation and remodeling. Am J Respir Crit Care Med 161:1720-1745.

Burke-Gaffney A and Hellewell PG (1998). A CD18/ICAM-1dependent pathway mediates eosinophil adhesion to bronchial epithelial cells. Am J Respir Cell Mol Biol 19:408-418.

Campbell EM, Kunkel SL, Strieter RM, and Lukacs NW (1998). Temporal role of chemokines in a murine model of cockroach allergen-induced airway hyperreactivity and eosinophilia. J Immunol 161:7047-7053.

Cohn L (2001). Food for thought: Can immunological tolerance be induced to treat asthma? Am J Respir Cell Mol Biol 24:509-512.

Coyle AJ, Uchida D, Ackerman SJ, Mitzner W, and Irvin CG (1994). Role of cationic proteins in the airway. Hyperresponsiveness due to airway inflammation. Am J Respir Crit Care Med 150:S63-S71.

Frigas E, Loegering DA, Solley GO, Farrow GM, and Gleich GJ (1981). Elevated levels of the eosinophil granule major basic protein in the sputum of patients with bronchial asthma. Mayo Clin Proc 56:345-353.

Fukuda T, Fukushima $\mathrm{Y}$, Numao T, Ando N, Arima M, Nakajima H, Adachi T, Motojima S, and Makino S (1996). Role of interleukin-4 and vascular cell adhesion molecule- 1 in selective eosinophil migration into the airways in allergic asthma. Am J Respir Cell Mol Biol 14:84-94.

Garcia-Zepeda EA, Rothenberg ME, Ownbey RT, Celestin J, Leder P, and Luster AD (1996). Human eotaxin is a specific chemoattractant for eosinophil cells and provides a new mechanism to explain tissue eosinophilia. Nat Med 2:449456 .

Gonzalo JA, Lloyd DM, Kremer L, Finger E, Martinez-A C, Siegelman MH, Cybulsky M, and Gutierrez-Ramos JC (1996). 
Eosinophil recruitment to the lung in a murine model of allergic inflammation. The role of $\mathrm{T}$ cells, chemokines and adhesion receptors. J Clin Invest 98:2332-2345.

Gonzalo JA, Lloyd CM, Wen D, Albar JP, Wells TN, Proudfoot A, Martinez-A C, Dorf M, Bjerke T, Coyle AJ, and GutierrezRamos JC (1998). The coordinated action of CC chemokines in the lung orchestrates allergic inflammation and airway hyperresponsiveness. J Exp Med 188:157-167.

Griffiths-Johnson DA, Collins PD, Jose PJ, and Williams TJ (1997). Animal models of asthma: role of chemokines. Methods Enzymol 288:241-266.

Guilbert M, Ferland C, Bosse M, Flamand N, Lavigne S, and Laviolette M (1999). 5-oxo-6,8,11,14-eicosatetraenoic acid induces important eosinophil transmigration through basement membrane components: Comparison of normal and asthmatic eosinophils. Am J Respir Cell Mol Biol 21:97-104.

Henricks PA, Bloemen PG, and Nijkamp FP (1997). Adhesion molecules and the recruitment of eosinophils to the airways. Res Immunol 148:18-28.

Jatakanon A, Lim S, and Barnes PJ (2000). Changes in sputum eosinophils predict loss of asthma control. Am $\mathrm{J}$ Respir Crit Care Med 161:64-72.

Kita H and Gleich GJ (1996). Chemokines active on eosinophils: Potential roles in allergic inflammation. J Exp Med 183:2421-2426.

Korsgren M, Erjefalt JS, Korsgren O, Sundler F, and Persson CGA (1997). Allergic eosinophil-rich inflammation develops in lungs and airways of $B$ cell-deficient mice. J Exp Med 185:885-892.

Kroegel C, Virchow JC, Luttmann W, Walker C, and Warner JA (1994). Pulmonary immune cells in health and disease: The eosinophil leucocyte (Part I). Eur Respir J 7:519-543.

Kumar RK, Temelkovski J, McNeil HP, and Hunter N (2000a). Airway inflammation in a murine model of chronic asthma: Evidence for a local humoral immune response. Clin Exp Allergy 30:1486-1492.

Kumar RK, Walsh C, and Cooke BE (2000b). Reduced non-specific fluorescence of paraffin sections by use of a novel red-emitting dye. J Histotechnol 23:99-102.

Kumar RK, Herbert C, Yang M, Koskinen AML, McKenzie ANJ, and Foster PS (2002). Role of interleukin-13 in eosinophil accumulation and airway remodelling in a mouse model of chronic asthma. Clin Exp Allergy (in press).

Laitinen LA, Laitinen A, and Haahtela T (1993). Airway mucosal inflammation even in patients with newly diagnosed asthma. Am Rev Respir Dis 147:697-704.

Lamkhioued B, Renzi PM, Abi-Younes S, Garcia-Zepada EA, Allakhverdi Z, Ghaffar O, Rothenberg MD, Luster AD, and Hamid Q (1997). Increased expression of eotaxin in bronchoalveolar lavage and airways of asthmatics contributes to the chemotaxis of eosinophils to the site of inflammation. $\mathrm{J}$ Immunol 159:4593-4601.

Leckie MJ, ten Brinke A, Khan J, Diamant Z, O'Connor BJ, Walls CM, Mathur AK, Cowley HC, Chung KF, Djukanovic R, Hansel TT, Holgate ST, and Barnes PJ (2000). Effects of an interleukin-5 blocking monoclonal antibody on eosinophils, airway hyper-responsiveness, and the late asthmatic response. Lancet 356:2144-2148.

Li L, Xia Y, Nguyen A, Lai YH, Feng L, Mosmann TR, and Lo $D$ (1999). Effects of Th2 cytokines on chemokine expression in the lung: IL-13 potently induces eotaxin expression by airway epithelial cells. J Immunol 162:2477-2487.

Matsukura A, Stellato C, Georas SN, Casolaro V, Plitt JR, Miura K, Kuosawa S, Schindler U, and Schleimer RP (2001). Interleukin-13 upregulates eotaxin expression in airway epithelial cells by a STAT6-dependent mechanism. Am J Respir Cell Mol Biol 24:755-761.

McKenzie GJ, Emson CL, Bell SE, Anderson S, Fallon P, Zurawski G, Murray R, Grencis R, and McKenzie AN (1998). Impaired development of Th2 cells in IL-13-deficient mice. Immunity 9:423-432.

Montefort S, Gratziou C, Goulding D, Polosa R, Haskard DO, Howarth PH, Holgate ST, and Carroll MP (1994). Bronchial biopsy evidence for leukocyte infiltration and upregulation of leukocyte-endothelial cell adhesion molecules 6 hours after local allergen challenge of sensitized asthmatic airways. $\mathrm{J}$ Clin Invest 93:1411-1421.

Mould AW, Matthei KI, Young IG, and Foster PS (1997). Relationship between interleukin- 5 and eotaxin in regulating blood and tissue eosinophilia in mice. J Clin Invest 99:10641071.

Nakajima H, Sano H, Nishimura T, Yoshida S, and Iwamoto I (1994). Role of vascular cell adhesion molecule 1/very late activation antigen 4 and intercellular adhesion molecule $1 /$ lymphocyte function-associated antigen 1 interactions in antigen-induced eosinophil and T cell recruitment into tissue. J Exp Med 179:1145-1154.

Nakamura $\mathrm{H}$, Weiss ST, Israel E, Luster AD, Drazen JM, and Lilly CM (1999). Eotaxin and impaired lung function in asthma. Am J Respir Crit Care Med 160:1952-1956.

Rothenberg ME, Zimmermann N, Mishra A, Brandt E, Birkenberger LA, Hogan SP, and Foster PS (1999). Chemokines and chemokine receptors: Their role in allergic airway disease. $\mathrm{J}$ Clin Immunol 19:250-265.

Shaver JR, Zangrilli JG, Cho SK, Cirelli RA, Pollice M, Hastie AT, Fish JE, and Peters SP (1997). Kinetics of the development and recovery of the lung from IgE-mediated inflammation: Dissociation of pulmonary eosinophilia, lung injury, and eosinophil-active cytokines. Am J Respir Crit Care Med 155:442-448.

Temelkovski J, Hogan SP, Shepherd DP, Foster PS, and Kumar RK (1998). An improved murine model of asthma: Selective airway inflammation, epithelial lesions and increased methacholine responsiveness following chronic exposure to aerosolised allergen. Thorax 53:849-856.

Teran LM (2000). CCL chemokines and asthma. Immunol Today 21:235-242.

Teran LM, Mochizuki M, Bartels J, Valencia EL, Nakajima T, Hirai K, and Schroder JM (1999). Th1- and Th2-type cytokines regulate the expression and production of eotaxin and RANTES by human lung fibroblasts. Am J Respir Cell Mol Biol 20:777-786.

Tillie-Leblond I, Hammad H, Desurmont S, Pugin J, Wallaert B, Tonnel AB, and Gosset P (2000). CC chemokines and interleukin- 5 in bronchial lavage fluid from patients with status asthmaticus: Potential implication in eosinophil recruitment. Am J Respir Crit Care Med 162:586-592.

Weller PF (1991). The immunobiology of eosinophils. N Engl J Med 324:1110-1118.

Woltmann G, McNulty CA, Dewson G, Simon FA, and Wardlaw AJ (2000). Interleukin-13 induces PSGL-1/P-selectin- 
dependent adhesion of eosinophils, but not neutrophils, to human umbilical vein endothelial cells under flow. Blood 95:3146-3152.

Yamamoto H, Sedgwick JB, and Busse WW (1998). Differential regulation of eosinophil adhesion and transmigration by pulmonary microvascular endothelial cells. J Immunol 161:971-977.

Ying S, Robinson DS, Meng Q, Rottman J, Kennedy R, Ringler DJ, Mackay CR, Daugherty BL, Springer MS, Durham SR, Williams TJ, and Kay AB (1997). Enhanced expression of eotaxin and CCR3 mRNA and protein in atopic asthma. Association with airway hyperresponsiveness and predominant co-localization of eotaxin mRNA to bronchial epithelial and endothelial cells. Eur J Immunol 27:3507-3516.
Ying S, Robinson DS, Meng Q, Barata LT, McEuen AR, Buckley MG, Walls AF, Askenase PW, and Kay AB (1999). $\mathrm{C}-\mathrm{C}$ chemokines in allergen-induced late-phase cutaneous responses in atopic subjects: Association of eotaxin with early 6-hour eosinophils, and of eotaxin-2 and monocyte chemoattractant protein-4 with the later 24-hour tissue eosinophilia, and relationship to basophils and other C-C chemokines (monocyte chemoattractant protein-3 and RANTES). J Immunol 163:3976-3984.

Zhu Z, Homer RJ, Wang Z, Chen Q, Geba GP, Wang J, Zhang $Y$, and Elias JA (1999). Pulmonary expression of interleukin-13 causes inflammation, mucus hypersecretion, subepithelial fibrosis, physiologic abnormalities, and eotaxin production. J Clin Invest 103:779-788.

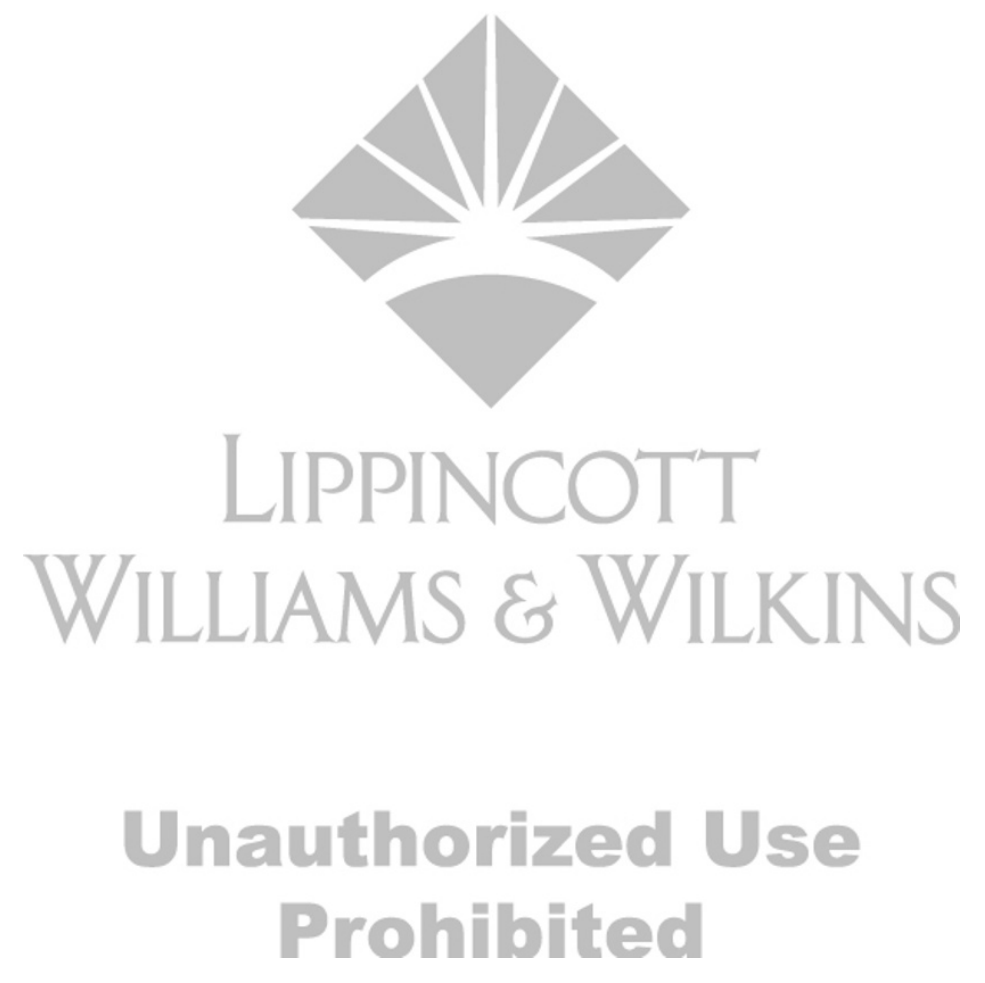

